\title{
DEVELOPMENT OF ATYPICAL AMIODARONE KERATOPATHY IN A CORNEAL GRAFT
}

\author{
N. K. ROGERS ${ }^{1}$, D. I. BOWEN ${ }^{1}$ and B. A. NOBLE ${ }^{2}$ \\ Harrogate and Leeds
}

\begin{abstract}
SUMMARY
The presence of fine epithelial deposits in a whorled pattern (cornea verticillata) as a consequence of treatment with amiodarone is well documented. We present a case of amiodarone keratopathy in a grafted cornea which is atypical in that the orientation of the pattern is rotated through nearly $90^{\circ}$ to that normally observed. This observation runs counter to the hypothesis that cornea verticillata is a manifestation of the line of lid closure. We speculate on the mechanism directing the migrational pathways of epithelial cells.
\end{abstract}

\section{CASE REPORT}

A male (born 1915) presented in 1985 with recurrent herpes simplex keratitis in the left eye (visual acuity 6/6). $\mathrm{He}$ also had bilateral chronic open angle glaucoma, controlled by topical beta-blockers. The left cornea became progressively thin, vascularised and had recurrent episodes of ulceration over the ensuing years; the best vision deteriorated to 6/60. In 1986 he lost useful vision in the right eye after a central retinal vein occlusion with subsequent cystoid macular oedema.

In 1989 he underwent a left penetrating keratoplasty. The donor was a 57-year-old woman whose left eye was enucleated for a choroidal malignant melanoma with associated retinal detachment. She had never suffered from cardiac disease or taken amiodarone. An $8 \mathrm{~mm}$ button was trephined from the whole donor eye (after epithelial debridement) within an hour or so of enucleation. Histological examination of the remnants later showed no evidence of scleral invasion or extension into the anterior chamber. An $8 \mathrm{~mm}$ button was trephined from the host and the donor material was fixed by four cardinal sutures and a continuous 10-0 nylon suture. Post-operative notes record a clear graft, but no documentation on the re-

From: 'Department of Ophthalmology, Harrogate District Hospital, Harrogate; ${ }^{2}$ Department of Ophthalmology, The General Infirmary at Leeds, Leeds, UK.

Correspondence to: Dr. N. Rogers, Department of Ophthalmology, Clarendon Wing, The General Infirmary at Leeds, Belmont Grove, Leeds LS2 9NS, UK. epithelialisation process. At 6 weeks the vision was $6 / 12$ (-5.50DS/+6.50DC axis 115).

In August 1991 the patient was admitted with chest pain and a supraventricular tachycardia of 190 beats/min which was eventually brought under control with amiodarone after several attempts with other anti-arrhythmic agents and cardioversion. At this stage a resting bradycardia was observed and topical beta-blockers were stopped. In June 1992 he underwent right trabeculectomy. His maintenance dose of amiodarone is $200 \mathrm{mg}$ once daily. In August 1992 he was noted to have bilateral amiodarone keratopathy. This was typical in the right eye, but in the grafted eye the spindle was roughly perpendicular to the normal orientation (Figs. 1, 2).

\section{DISCUSSION}

Amiodarone is a class III anti-arrhythmic agent effective against a wide range of arrhythmias. Its catalogue of side effects includes dysthyroid disease, interstitial pneumonitis, peripheral neuropathy, pigmentation and photosensitivity, hepatitis and bilateral corneal deposits. ${ }^{1}$

The incidence of amiodarone keratopathy is variously estimated to be between $60 \%$ and $98 \%$. The presentation is normally occult, but a fraction of patients (less than 12\%) report mild lid irritation, photophobia, haloes and blurring. The degree of keratopathy is variable and although there is a small correlation with dose and duration, this is not conclusive. ${ }^{2-6}$

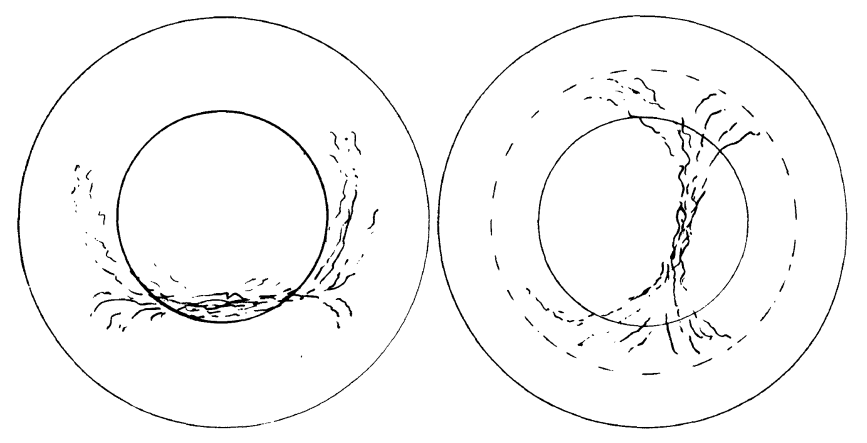

Fig. 1. Schematic representation of the vortex keratopathy in the patient's two eyes. Left: Right eye, normal orientation. Right: Left eye, orientation in graft. 


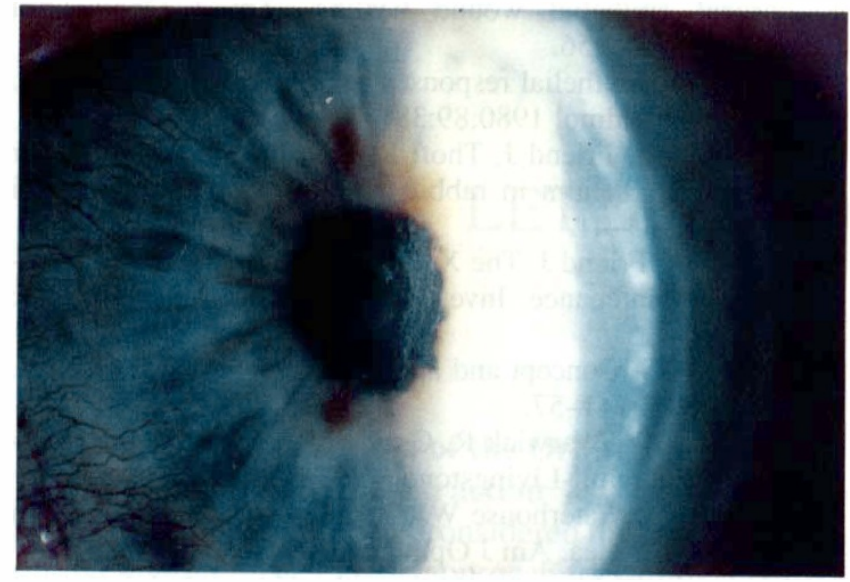

Fig. 2. Anterior segment photograph showing the atypical orientation of the amiodarone keratopathy.

Epithelial vortex patterns are only visible on biomicroscopy. They are found in Fabry's disease, Hudson-Stahli lines of iron deposition, the striate melanokeratosis of pigmented patients with resolving keratitis, and as a side effect of amiodarone, anti-malarials, phenothiazines ${ }^{7.8}$ and other drugs (see Table I). Two mechanisms have been proposed for production of the pattern. The first is that the predominant horizontal line across the lower two-thirds of the cornea corresponds to the line of lid closure and that the deposits result directly from the concentration of the drug in the tears. ${ }^{9,10}$ An alternative proposal is that the lines are a manifestation of the centripetal trajectory of migrating epithelial cells from a non-uniform distribution of stem cells at the limbus. The direction of movement is thought to follow a pattern similar to that of water flowing down a plug hole, with the point of the vortex in the midline at the junction of the lower and middle third of the cornea. $^{4,8}$

Since the clinical appearance of the drug-induced deposits is indistinguishable from that of Fabry's disease (alpha-galactosidase A deficiency) it has been suggested that these drugs produce an iatrogenic sphingolipidosis. ${ }^{11-15}$ Histological studies of amiodarone keratopathy show that the deposits are in the epithelium, where $0.2-$ $0.5 \mu \mathrm{m}$ lamellated cytoplasmic inclusion bodies are found. The precise position within the epithelium is a matter of debate, ${ }^{14.16}$ but in Fabry's disease the predominant position is in the basal layers. ${ }^{11}$ The appearance on light microscopy of the deposits secondary to anti-malar-

Table I. Medications implicated in the production of cornea verticillata

Amiodarone

Phenothiazines

Anti-malarials

Clofazimine

Monobenzone

Tilorone

Suramin

Naproxen

Indomethacin

Pethidine
See text

Ohman and Wahlberg ${ }^{25}$

Walinder $^{26}$

Hedges et al. ${ }^{27}$

Weiss et al. ${ }^{28}$

Teich et al. ${ }^{29}$

Szmyd and Perry ${ }^{30}$

Bernstein $^{31}$

Hobbs et al. ${ }^{32}$ ial use is identical, but electron microscopy does not reveal lamellation of the inclusion bodies. ${ }^{16}$

The molecular mechanism of production of these deposits is a matter of some conjecture. One possibility is that the drug forms a complex with the lipid substrate of the enzyme and renders it unacceptable to the enzyme. As more of the drug-lipid complex accumulates in the cells it is incorporated into lysosomal inclusion bodies. ${ }^{12,14} \mathrm{An}$ alternative is that the drug interacts with alpha-galactosidase $\mathrm{A}$ or a related enzyme and alters its specificity for the normal lipid substrate, which is consequently deposited in the cells. It has been shown that whereas chloroquine is an inhibitor of alpha-galactosidase A, amiodarone is not, ${ }^{15}$ so it may be that different mechanisms are at work producing the same clinical appearance.

Centripetal migration of epithelial cells is certain in the traumatised cornea as evidenced by the common clinical appearances of healing corneal wounds. ${ }^{17,18}$ Such movement has also been established in epithelial responses to keratoplasty by observing the migration of epithelial microcysts ${ }^{19}$ and the distribution of sex chromatin after graft swapping between male and female rabbits. ${ }^{20}$ In this latter experiment, donor epithelium was shown to be gradually replaced by that of the host and there was no evidence of donor-to-host (i.e. centrifugal) migration. The same process has been postulated in normal epithelium ${ }^{19,21}$ and the concept of a limbal stem cell has been invoked to account for cell proliferation providing a supply of cells to maintain the corneal epithelium. ${ }^{22}$ The presence of a reproducible pattern of corneal epithelial deposits, but in an altered orientation, suggests to us that the movement of epithelial cells is not a random two-dimensional Brownian diffusion process but is directed by some underlying mechanism, presumably at the level of Bowman's membrane. Organised migration of differentiating cells is a well-documented phenomenon in the histogenesis of the neural tube. ${ }^{23} \mathrm{~A}$ similar mechanism could be envisaged directing the movement of differentiating ectodermal derivatives (corneal epithelial cells) over mesenchymal tissue (corneal stroma).

\section{CONCLUSION}

To our knowledge there has been only one other report of amiodarone keratopathy in relation to a corneal graft, and that related its disappearance from the donor button postoperatively. ${ }^{24}$ This case runs counter to the supposition that this condition is determined by the line of lid closure. Furthermore the presence of the typical vortex pattern in the graft, but in a different orientation, suggests that there might be some histoarchitectural substrate at the level of Bowman's membrane that determines the trajectory of epithelial cells.

Key words: Amiodarone, Corneal graft, Cornea verticillata.

\section{REFERENCES}

1. Wilson JS, Podrid PJ. Side effects from amiodarone. Am Heart J 1991;121:158-71.

2. Nielson CE, Andreasen F, Bjerregaard P. Amiodarone 
induced cornea verticillata. Acta Ophthalmol (Copenh) 1983;61:474-80.

3. Ingram DV, Jaggarao NSV, Chamberlain DA. Ocular changes resulting from therapy with amiodarone. $\mathrm{Br} \mathrm{J}$ Ophthalmol 1982;66:676-9.

4. Orlando RG, Dangel ME, Schaal SF. Clinical experience and grading of amiodarone keratopathy. Ophthalmology 1984;91:1184-7.

5. Kaplan LJ, Cappaert WE. Amiodarone keratopathy. Arch Ophthalmol 1982;100:601-2.

6. Klingele TJ, Alves LE, Rose EP. Amiodarone keratopathy. Ann Ophthalmol 1984;16:1172-6.

7. Francois J. Cornea verticillata. Doc Ophthalmol 1969;27: 235-50.

8. Bron AJ. Vortex patterns of the corneal epithelium. Trans Ophthalmol Soc UK 1973;93:455-72.

9. Gass JDM. The iron lines of the superficial cornea. Arch Ophthalmol 1964;71:348-58.

10. Feiler-Ofry V, Lazar M, Solomon A, Godel V. Amiodarone keratopathy. Ophthalmologica 1980;180:257-61.

11. Font RL, Fine BS. Ocular pathology in Fabry's disease. Am J Ophthalmol 1972;73:419-30.

12. Lullmann H, Lullmann-Rauch R, Wassermann O. Drug induced phospholipidoses. Crit Rev Toxicol 1975;4: $185-218$

13. D'Amico DJ, Kenyon KR. Drug induced lipidoses of the cornea and conjunctiva. Int Ophthalmol 1981;4:67-76.

14. D'Amico DJ, Kenyon KR, Ruskin JN. Amiodarone keratopathy: drug induced lipid storage disease. Arch Ophthalmol 1981;99:257-61.

15. Whitley CB, Tsai MY, Heger JJ, Prystowsky EN, Zipes DP. Amiodarone phenocopy of Fabry's keratopathy. J Am Med Assoc 1983;249:2177-8.

16. Hirst LW, Sanborn G, Green WR, Miller NR, Heath WD. Amodiaquine ocular changes. Arch Ophthalmol 1982;100: 1300-4.

17. Dua HS, Forrester JV. Clinical patterns of corneal epithelial wound healing. Am J Ophthalmol 1987;104:481-9.

18. Dua HS, Forrester JV. The corneoscleral limbus in human corneal epithelial wound healing. Am J Ophthalmol 1990;110:646-56.

19. Kaye DB. Epithelial responses in penetrating keratoplasty. Am J Ophthalmol 1980;89:381-7.

20. Kinoshita S, Friend J, Thoft RA. Sex chromatin of donor corneal epithelium in rabbits. Invest Ophthalmol Vis Sci 1981;21:434-41.

21. Thoft RA, Friend J. The X, Y, Z hypothesis of corneal epithelial maintenance. Invest Ophthalmol Vis Sci 1983;24: 1442-3.

22. Tseng SCG. Concept and application of limbal stem cells. Eye 1989;3:141-57.

23. Williams PL, Warwick R. Gray's anatomy, 36th ed. Edinburgh: Churchill-Livingstone, 1983:157ff.

24. Garrett SN, Waterhouse WJ, Parmley VC. Amiodarone in the donor cornea. Am J Ophthalmol 1988;105:425-6.

25. Ohman L, Wahlberg I. Ocular side effects of clofazimine. Lancet 1975;2:933-4

26. Walinder PE, Gip L, Stempa M. Corneal changes in patients treated with clofazimine. Br J Ophthalmol 1976;60:526-8.

27. Hedges TR, Kenyon KR, Hanninen LA, Mosher DB. Corneal and conjunctival effects of monobenzone in patients with vitiligo. Arch Ophthalmol 1983;101:64-8.

28. Weiss JN, Weinberg RS, Regelson W. Keratopathy after oral administration of tilorone hydrochloride. Am J Ophthalmol 1980;89:46-53.

29. Teich SA, Handwerger S, Mathur-Wagh U, Yancovitz S, Desnick RJ, Mildvan D. Toxic keratopathy associated with suramin therapy. N Engl J Med 1986;314:1455-6.

30. Szmyd L, Perry HD. Keratopathy associated with the use of naproxen. Am J Ophthalmol 1985;99:598.

31. Bernstein HN. Some iatrogenic ocular diseases from systemically administered drugs. Int Ophthalmol Clin 1970;10:553-619.

32. Hobbs HE, Eadie SP, Somerville F. Ocular lesions after treatment with chloroquine. $\mathrm{Br} \mathrm{J}$ Ophthalmol. 1961;45: 284-97. 